\title{
COST COMPARISON OF ARTIFICIAL INSEMINATION AND NATURAL SERVICE IN SHEEP BREEDING SYSTEM
}

\author{
Mohammad ASADUZZAMAN 1 , Amit SAHA², Md. Golam Shahi ALAM ${ }^{2}$ and Farida Yeasmin BARI ${ }^{2}$ \\ 1 Upazilla Livestock Officer, Department of Livestock Services, Farmgate, Dhaka-1215, Bangladesh \\ 2Department of Surgery and Obstetrics, Bangladesh Agricultural University, Mymensingh-2202, Bangladesh \\ Email: faridabari06@gmail.com; (D) ORCiD: 0000-0002-1574-9263 \\ Supporting Information
}

\begin{abstract}
The cost information of animal breeding is a major concern in the farming system when making management and production system improvement decisions. Moreover, it is important to identify the most important cost positions and perspectives of the production process. This study is, therefore aimed to estimate, identify, and compare the cost contribution and breeding cost of artificial insemination (Al) vs. natural service in sheep production systems using frozen ram semen. Natural service by hand mating was performed to breed the ewes $(n=24)$ in estrus detected by a teaser ram maintained in a flock of 40 ewes. Artificial insemination was performed in synchronized ewes $(n=10)$ after cervical ripening treatment using intramuscular injection of oxytocin. Breeding and performance costs were estimated by analyzing the cost associated factors. Per head insemination cost and cost per pregnancy in an artificial breeding program ( $\$ 2.80$ and $\$ 5.59)$ were higher than natural breeding program (\$1.40 and $\$ 1.77)$ in sheep production. Ram depreciation cost, feed cost, and maintenance cost-shared the maximum cost in natural breeding, while the frozen semen cost, a special type of eccentric Al pipette cost, and hormone cost provoke the increased cost as the major constraints of the artificial breeding program. Minimizing the constraints and improving efforts in the conception rate of artificial insemination, farmers or producers will be benefited from natural breeding through rapid exploitation of the desired genetics cost-effectively.
\end{abstract}

Keywords: Artificial insemination, Cost comparison, Natural service, Semen, Sheep production.

\section{INTRODUCTION}

The semen delivery system denotes the type of service used in animal breeding (See, 2014). The natural service is the common and traditional semen delivery system, which is performed by pasture mating, pen mating, or hand mating. Another modern semen delivery system- artificial insemination (AI) is performed by vaginal, cervical, trans-cervical, and laparoscopic insemination using fresh diluted, chilled, or frozen semen (ICAR, 2012). Generally, Bangladeshi sheep are reared by the semi-intensive system with free grazing in the daytime and sheltered at night. Free mating occurs by the flock born under qualified ram or ram of a neighborhood in the pasture land. This is the common scenario of the smallholder sheep breeding system (pasture mating / free mating). Apart from this, farmers in some parts of the country, such as Chuadanga, Meherper, Chapainawabganj are conscious of selective breeding with Muzaffarnagari cross-sheep and becoming benefited in production. Another type of natural breeding - hand mating is commonly performed by the village farmers for their doe (she-goat) in the absence or crisis of buck. They go with their heated doe to the stud center and get 2-3 continuous services by a stud or buck in exchange for money.

Artificial insemination ( $\mathrm{Al}$ ) among all other breeding systems is the best means of distributing germ cells from male to many female lines within each ecosystem (Rozeboom, 2000). The Al in sheep has a great impediment in its widespread use are variability in fertility and application problems (Leboeuf et al., 2000; Flowers, 2013). The process of sheep artificial insemination, in particular, is one of the applications that are restricted by the morphological structure of the ewe cervix (Kershaw et al., 2005). The type of sperms to be used in Al is also another important point of consideration. The chilled storage of semen cannot be stored for longer and transport for a long period, and the difficulty of frozenthawed sperm to transmit and reach the cervix and fertilization site of ewe, respectively (Salamon and Maxwell, 1995; Fair et al. 2005). Despite various attempts to manipulate the cervix with advanced equipment and efficient insemination, the role of the cervical canal in regulating frozen sperm transport in ewes remains problematic due to the morphometric of the ewe cervical canal and external os (Aral et al., 2011). Laparoscopy and laparotomy have been used as effective methods for artificial insemination; however, they come at a high cost, take a long time, and require specialized equipment (Torrès and Sevellec, 1987; Evans and Maxwell, 1987). Cervix treatment to ripen and dilate for easy passage of insemination pipettes has been attempted by many researchers (Wulster-Radcliffe et al., 2004; Candappa et al., 2009). Masoudi et al. (2017) used oxytocin to dilate and facilitate the ewe cervix resulted in a higher pregnancy and lambing rate (60 percent).

To acquire the desired genetics in animals, producers need to be known the methods, cost, and benefits of the breeding system. Low-cost manufacturing is still essential for the company's survival. Moreover, to make an instructive/ 
constructive decision, each producer must know the production costs for their operation. Therefore, understanding the costs of producing pregnancies via various methods and their associated values is very important. The costs of producing pregnancy in synchronized ewes through natural service and artificial insemination are examined in this paper.

\section{MATERIALS AND METHODS}

\section{Study site}

At the Sheep Research Animal Farm, Bangladesh Agricultural University, Mymensingh, and Nilakhir Char, Sadar Upazilla, Mymensingh, a cost comparison of reproductive success between natural service and transcervical artificial insemination programs in indigenous ewes were conducted. The research was carried out from March to September 2020. The study site is located from $24.730 \mathrm{~N}$ latitude to $90.440 \mathrm{E}$ longitude and receives a mean $174 \mathrm{~mm}$ of rainfall with the mean annual minimum to most temperatures vary from 16.46 to $29.13^{\circ} \mathrm{C}$.

\section{Ethical regulation}

Animal Experimental Ethics Committee (AEEC) of BAU, Mymensingh, Bangladesh (Ref. no. AEEC/ DSO-BAU/02/ 2018) accepted the study protocols.

\section{Natural breeding}

The natural breeding program used in indigenous non-pregnant ewes at Bangladesh Agricultural University's Sheep Research Animal Farm in Mymensingh. They were grazed freely on natural pasture for $5 \mathrm{~h}$ with supplementation mixtures of approximately 200-250 gm. per head, and consist of maize grit, wheat bran with di-calcium phosphate, and salt (NaCl). They were provided three times the amount of safe drinking water ad libitum and dewormed routinely. A teaser ram was maintained within a flock of $\mathbf{4 0}$ breeding ewes. The teaser was observed running the ewes for an hour to identify the ewes on heat from time to time to make free of the shelter house daily in the morning. A ewe or ewes found in heat by teaser were separated into smaller enclosers or pens. Each heated ewe was allowed to be mated by a ram for up to 3 continuous matings (Ronald et al., 2013).

\section{Artificial breeding}

The ewes were kept on pasture from morning to dusk by a farmer's flocks, with free access to safe drinking water. The non-pregnant ewes were pre-synchronized using intramuscular injections $(0.7 \mathrm{ml} / \mathrm{ewe})$ of Prostaglandin $F_{2 \alpha}\left(P_{G F} F_{2 \alpha}\right.$ (Ovupost ${ }^{\circledR}, 250 \mathrm{~g}$ of cloprostenol sodium/ $\mathrm{ml}$ injection, Bayer, New Zealand Limited). On the day of artificial insemination, an aproned ram detected the oestrus ewes and separated them. The cervical structure was ripened and relaxed by injecting oxytocin (OT) (Linda-S ${ }^{\circledR}$ DS, Synthetic Oxytocin USP 10 IU/ml, Nuvista Pharma Limited, Gazipur, Bangladesh) at a dose rate of $50 \mathrm{IU}$ per heated animal. The artificial insemination was performed within 2 minutes following 20 min of OT injection. Two straws of frozen semen were used in artificial insemination (Ronald et al., 2013), while a straw contained $200 \times 10^{6} / 0.25 \mathrm{ml}$ of spermatozoa with $\geq 40 \%$ motility.

\section{Budget assumption}

The number of rams is an important factor in the natural breeding cost assumption. A ram can mate and breed between 30 - 40 ewes in a season or other terms between 1 or 2 ewes per ram per day (Henning, 2010). A total of 24 ewes exhibited heat for 30 days and were given natural services. Therefore, we used a breeding ram and were enough for natural service at heated ewe or ewes on the day of breeding. The purchase cost of a breeding ram was estimated as $\$ 70.81$ and the culling value was estimated as $\$ 57.83$ at the rate of $\$ 4.72$ per $\mathrm{kg}$ of meat (carcass weight). These values were used in the depreciation cost calculation. The daily feed cost for a ram was $\$ 0.34$; ram maintenance cost (variable cost) was estimated as $\$ 0.27$ based on $\$ 122.74$ for 15 rams herd per month. The labor cost was estimated at the time spent on 3 natural services. The health problem cost was not considered in this study. Ram tended not to receive vaccinations. Time consumed in transportation was not considered for cost calculation.

The estimates for a custom artificial insemination cost include consumable materials cost, technician cost, labor cost, hormone cost, and semen cost. Al pipette, lube, paper towels, and alcohol spray constitute the consumable item costs. A piece of Al pipette, about $5 \mathrm{gm}$ of lube (KLY jelly), 5 pieces of paper towels (hand tissues), and $2 \mathrm{ml}$ of $70 \%$ ethyl alcohol spray are the consumable materials needed to perform artificial insemination in the ewe. The single Al pipette (Minitube) costs $\$ 0.59$ while the other consumable materials cost $\$ 0.12$. Technician cost and labor cost were estimated according to project roles approved by Bangladesh Agricultural University Research System (BAURES) which was \$4.72 - \$ 5.90 daily for 6 - $8 \mathrm{~h}$ of work service. Hormone cost was estimated as per available market value. Per dose frozen cost was estimated as per dose of frozen products, and the required component of diluent and the calculated cost per straw frozen semen were about $\$ 0.49$. The pregnancy was confirmed after 50 to 60 days of artificial and natural breeding using DRAMINSKI Animal profi - a portable ultrasound scanner (Poland). The cost of ultrasonography was not considered in the budget estimation.

\section{RESULTS AND DISCUSSION}

The costs of natural service and artificial breeding are shown in Tables 1 and 2, respectively, with a cost comparison shown in Figure 1. In this study, we observed higher per head insemination cost and cost per pregnancy in an artificial 
breeding program (\$2.80 and \$5.59) than the natural breeding program (\$1.40 and \$1.77) of the sheep production system. Ram depreciation cost, feed cost, and maintenance cost-shared the maximum cost in natural breeding, while the frozen semen cost, a special type of eccentric Al pipette cost, and hormone cost provoke the increased cost as the major constraints of the artificial breeding program.

The cost of artificial breeding was about $50.11 \%$ higher than natural breeding cost. The breeding cost comparison especially for sheep breeding is scarce. The current findings, however, were consistent with those of Jacobsen (2010), who discovered that the natural breeding cost per head in a herd of 20 cows with a bull was 58.35 dollars per head. The natural service (NS) is cheaper, realistic of choice for more operations, less labor-intensive, but it takes longer to introduce new genetics, produce ununiformed herd that incurs management constraints. In Al breeding, everyone has access to rams with high genetic merit, which improve lamb performance and provide the option to sell in a value-added market (Jacobsen, 2010). The farmers will have to adopt Al while the economic and management constraints are identified to use it. In our present findings, synchronization and semen cost are the major candidates of constraints in this regard. The higher cost of frozen semen is due to the small volume of ejaculates with few rams and small quantities of frozen straw production in our box freezing system. This can be minimized by using the large volume of semen from many rams through bio-freezing production. Despite longer frozen semen storage, the semen cost can also be minimized using diluted fresh and chilled semen. The higher hormonal cost can be omitted from Al breeding expenditure by keeping a teaser ram in a flock only to detect an oestrus ewe.

The data on reproductive traits of sheep of natural mating and artificial insemination with frozen semen are presented in Tables 1 and 2. The pregnancy rate in naturally bred sheep was higher than in Al sheep. However, this type of work of cost comparison of in sheep breeding methods is scarce; the results of the present findings are in agreement with the observation of pregnancy rate by Agossou and Koluman (2018) in natural and artificial breeding of Alpine goats were to be $90 \%$ and $70 \%$; in Zoo-technical sheep, Allaoui et al. (2014) found fertility rates of 86.70 percent vs. 64 percent for free mating vs. Al. The present pregnancy rate could be increased following Al using fresh or liquid ram semen. According to Valergakis et al. (2010) stated that more than $80 \%$ pregnancy rate can be achieved in Zootechnical sheep following $\mathrm{Al}$ with experienced technicians using fresh ram semen. The present result also showed a higher per ewe pregnancy cost in Al bred than naturally bred ewe. This variation is mainly due to the difference in pregnancy rates of the two breeding methods. This finding was suggested by Griffith et al. (2020) findings, who reported per head pregnancy cost in NS breeding as $\$ 57.14$, and the per head conception cost in TAl was $\$ 114.7$ with a 30-cow herd. The cost of breeding does not include the time and money spent in a herd to improve Al genetics. When this is taken into account, Al becomes even more profitable. There may be a notable and consistent market value variation while using high genetic seeds through Al. This genetic advantage of a breeding program contributes most to the variation in cost between NS and Al (Overton, 2005).

\section{Table 1 - Cost of natural service program in sheep production}

\begin{tabular}{lc} 
Cost components & Values \\
\hline No. of ewes brought under breeding program & 24 \\
Total time consumed $(0.18 \mathrm{~h} / \mathrm{head}$ NS $)$ & $4.32 \mathrm{~h}$ \\
Aggregated labor cost $(\$ 4.72 / 8 \mathrm{~h} /$ day) & $\$ 2.55$ \\
Feed cost $(\$ 0.33 /$ day/ram) for 30 days) & $\$ 9.91$ \\
Maintenance cost $(\$ 0.27 /$ day/ram for 30 days ) & $\$ 8.12$ \\
Ram depreciation cost & $\$ 12.98$ \\
Per head natural service cost & $\$ 1.40$ \\
Pregnancy rate $\%)$ & $79(24 / 19)$ \\
Cost per pregnancy & $\$ 1.77$ \\
\hline
\end{tabular}

\section{Table 2 - Cost of artificial insemination program in sheep production}

\begin{tabular}{lc} 
Cost components & Values \\
\hline No. of ewes brought under breeding program & 24 \\
Total time consumed $(0.18 \mathrm{~h} / \mathrm{head}$ NS) & $4.32 \mathrm{~h}$ \\
Aggregated labor cost $(\$ 4.72 / 8 \mathrm{~h} /$ day) & $\$ 2.55$ \\
Feed cost $(\$ 0.33 /$ day $/ \mathrm{ram})$ for 30 days) & $\$ 9.91$ \\
Maintenance cost $(\$ 0.27 /$ day/ram for 30 days $)$ & $\$ 8.12$ \\
Ram depreciation cost & $\$ 12.98$ \\
Per head natural service cost & $\$ 1.40$ \\
Pregnancy rate $(\%)$ & $79(24 / 19)$ \\
Cost per pregnancy & $\$ 1.77$ \\
\hline
\end{tabular}




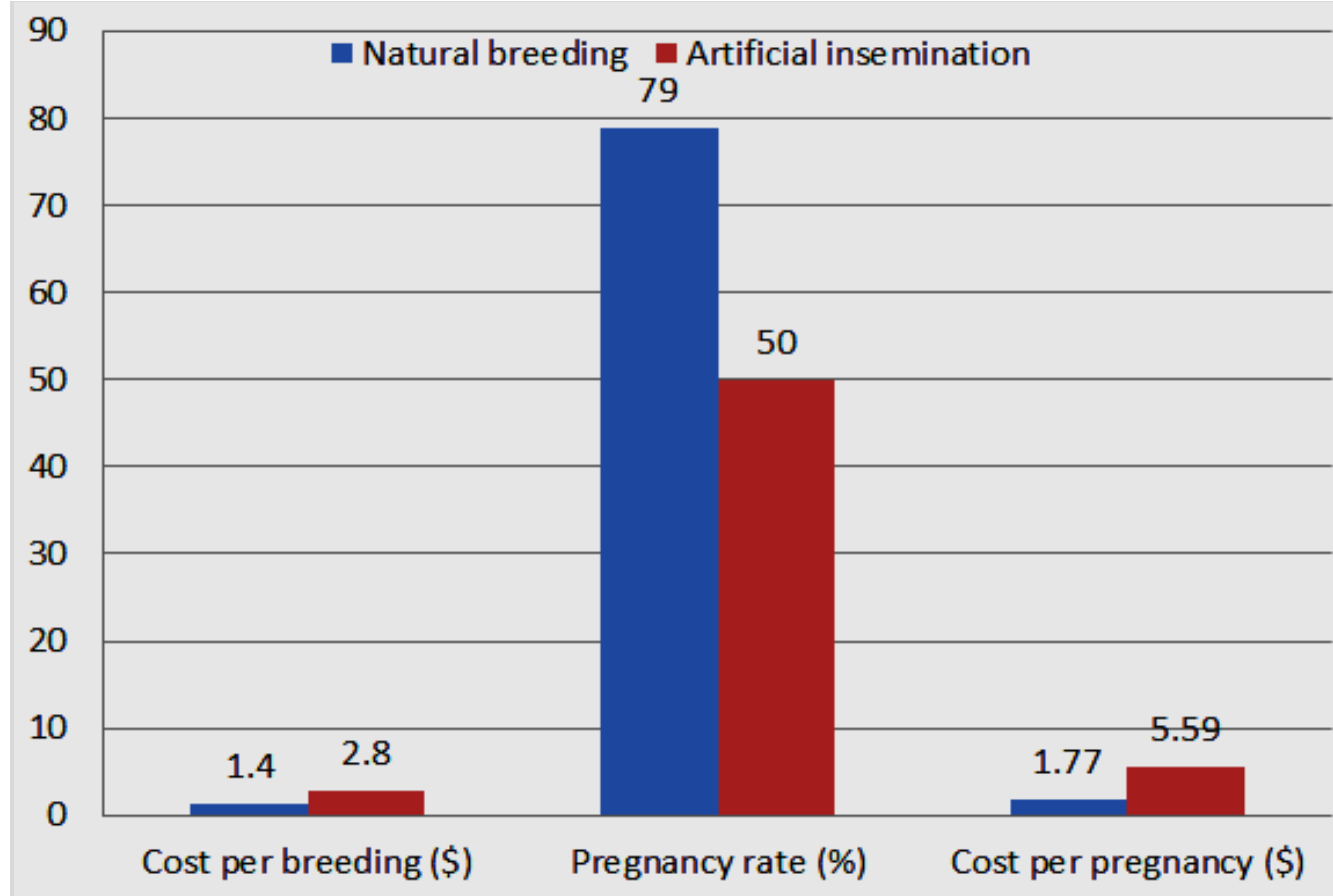

Figure 1 - The comparison between natural service and artificial insemination breeding

Before performing and adopting technology, especially the semen delivery system, may raise some questions- what, why, and how can it be done? To answer all questions and make the best decision, one needs to understand the cost and inputs associated with each system, the value of genetic merit, and the time consumed to achieve it. Although the present study showed a higher cost of artificial insemination with a lower pregnancy rate by comparing the natural service, it is still suggestive that Al is the incomparable tool for genetic progress and performance testing, and genetic evaluation. Moreover, it is a short and quicker process of exploitation of genetic values in terms of production.

\section{CONCLUSION}

In conclusion, it can be stated that artificial insemination in sheep breeding is more difficult to adapt than in cattle or buffalo. Moreover, because of the lower pregnancy rate, artificial breeding is more expensive than natural breeding. Minimizing the constraints and improving efforts in the concentration rate of artificial insemination, farmers or producers will be benefited from natural breeding through rapid exploitation of the desired genetics cost-effectively. Furthermore, it can be stated that the present cost comparison may have some assumptions that do not apply to another situation but may be of usable information to other operations.

\section{DECLARATIONS}

Corresponding author

Farida Yeasmin BARI: Email: faridabari06@gmail.com; (D) ORCID: 0000-0002-1574-9263

\section{Authors' contribution}

FY Bari contributed to the concept and write-up of the manuscript. M Asaduzzaman performed the study. A Saha assisted in performing the study, data arranging and calculation. MGS ALAM and all other authors read and approved the manuscript's contents.

\section{Conflict of interests}

The authors declare that they have no competing interests.

\section{Acknowledgments}

The author is greatly acknowledged to the reproduction personnel and staff of the Department of Surgery and Obstetrics, Bangladesh Agricultural University, Mymensingh-2202.

\section{REFERENCES}

Agossou DJ and Koluman N (2018). The effects of natural mating and artificial insemination using cryopreserved buck semen on reproductive performance in Alpine goats. Archives animal breeding, 61(4): 459-461. https://doi.org/10.5194/aab-61-459-2018

Allaoui A, Tlidjane M, Safsaf B and Laghrour W (2014). Comparative Study between Ovine Artificial Insemination and Free Mating in Ouled Djellal Breed. APCBEE Procedia, 8: 254-259. https://www.sciencedirect.com/science/article/pii/S221267081400116X 
Aral F, Temamogullari F and Aral SS (2011). Mechanical and pharmacologic applications of artificial insemination in ewes. Artificial Insemination in Farm Animals, Ed. by M. Manafi, IntechOpen Publication, Croatia. ISBN: 978-953-307-312-5. https://doi.org/10.5772/16564;

Candappa IB, Bainbridge HC, Price NT, Hourigan KR and Bartlewski PM (2009). A preliminary study on the suitability of Cervidil to induce cervical dilation for artificial insemination in ewes. Research in veterinary science, 87(2): 204-206. D0I: 10.1016/j.rvsc.2009.02.004

Evans G and Maxwell WC (1987). Salamons' artificial insemination of sheep and goats (No. Ed. 2). Butterworths. Link: https://www.cabdirect.org/cabdirect/abstract/19890169622

Fair S, Hanrahan JP, O'Meara CM, Duffy P, Rizos D, Wade M, Donovan A, Boland MP, Lonergan P and Evans ACO (2005). Differences between Belclare and Suffolk ewes in fertilization rate, embryo quality and accessory sperm number after cervical or laparoscopic artificial insemination. Theriogenology, 63(7): 1995-2005. DOI: 10.1016/j.theriogenology.2004.09.005

Flowers WL (2013). Triennial Reproduction Symposium: sperm characteristics that limit success of fertilization. Journal of Animal Science, 91(7): 3022-3029. https://doi.org/10.2527/jas.2012-5945

Griffith AP, Boyer CN, Rhinehart JD and Carter C (2020). Cost-Benefit Analysis of Timed Al and Natural Service in Beef Cattle, UTIA.TENNESSEE.EDU Extention paper No. 2325-2020-530). https://extension.tennessee.edu/publications/Documents/w899.pdf

Henning Jl, Mare FA, and Willemse BJ (2010). Profitability analysis of different reproduction methods with Dohne Merinos (No. 308-2016-5024). https://ideas.repec.org/p/ags/aaae10/113787.html

ICAR (2012): Indian Council of Agricultural Research, Breeding management of sheep and goat, Methods of mating, New Delhi (2009-2012) http://www.agritech.tnau.ac.in/expert_system/sheepgoat.

Jacobsen P (2010). Natural Breeding vs. Artificial Insemination: A Cost Comparison Analysis. http://www.uwyo.edu/agecon/what-we-do/seniortheses/2010_03_29_seniorthesis_pjacobsen.pdf

Kershaw CM, Khalid M, McGowan MR, Ingram K, Leethongdee S, Wax G, and Scaramuzzi RJ (2005). The anatomy of the sheep cervix and its influence on the transcervical passage of an inseminating pipette into the uterine lumen. Theriogenology, 64(5): 1225-1235. https://doi.org/10.1016/j.theriogenology.2005.02.017

Leboeuf B, Restall B, and Salamon S (2000). Production and storage of goat semen for artificial insemination. Animal reproduction science, 62(1-3): 113-141. https://doi.org/10.1016/s0378-4320(00)00156-1

Masoudi R, Shahneh AZ, Towhidi A, Kohram H, Akbarisharif A, Sharafi M, Zhandi M, Shahab-El-Deen MA. (2017). Cervical dilation and improvement of reproductive performance in fat-tailed ewes via cervical dilator treatments. Asian Pacific Journal of Reproduction. 6(2):93. http://dx.doi.org/10.12980/apjr.6.20170209

Overton MW (2005). Cost comparison of natural service sires and artificial insemination for dairy cattle reproductive management. Theriogenology, 64(3): 589-602. https://doi.org/10.1016/j.theriogenology.2005.05.015

Ronald BSM, Jawahar TP, Gnanaraj PT and Sivakumar T (2013). Artificial insemination in swine in an organized farm-A pilot study. Veterinary World, 6(9): 651-654. Doi: http://dx.doi.org/10.14202/vetworld.2013.651-654

Rozeboom KJ (2000). The benefits and constraints to widespread use of reproductive technology in the future. In Proceedings of the Manitoba Swine Seminar, pp. 63-70. https://projects.ncsu.edu/project/swine_extension/ncporkconf/2001/rozeboom.htm

Salamon S and Maxwell WJARS (1995). Frozen storage of ram semen II. Causes of low fertility after cervical insemination and methods of improvement. Animal Reproduction Science, 38(1-2): 1-36. https://doi.org/10.1016/0378-4320(94)01328-J

See MT (2014). Extension Swine Husbandry ANS 96-809S. http://www.ncsu.edu/project/swine extension/publications/factsheets/809s.htm

Torrès S and Sevellec CJRND (1987). Repeated superovulation and surgical recovery of embryos in the ewe. Reproduction Nutrition Development, 27(4): 859-863. https://rnd.edpsciences.org/articles/rnd/pdf/1987/06/RND_0181-1916_1987_27_4_ART0012.pdf

Valergakis GE, Gelasakis Al, Oikonomou G, Arsenos G, Fortomaris P and Banos G (2010): Profitability of a dairy sheep genetic improvement program using artificial insemination. Animal, 4(10): 1628-1633. https://doi.org/10.1017/S1751731110000832

Wulster-Radcliffe MC, Wang S, Lewis GSJT (2004). Transcervical artificial insemination in sheep: effects of a new transcervical artificial insemination instrument and traversing the cervix on pregnancy and lambing rates. Theriogenology, 62(6): 990-1002. https://doi.org/10.1016/j.theriogenology.2003.12.031 